\title{
Analysis of Hydroquinone and Its Ether Derivatives by Using Micellar Electrokinetic Chromatography (MEKC)
}

\author{
Seokmin Jang and Yongseong Kim* \\ Department of Chemistry, Kyungnam University, Kyungnam 631-701, Korea. *E-mail: kimys@kyungnam.ac.kr \\ Received January 4, 2005
}

Key Words : MEKC, Hydroquinone, Surfactant, Whitening cream

\begin{abstract}
Phenolic compounds are important in various industries. ${ }^{1}$ Among them, hydroquinone and its derivatives are widely utilized in the industrial processes including coal-tar production, paper manufacturing, photographic applications, and rubber production. ${ }^{2}$ They are also employed as monomer inhibitors, antioxidants, agricultural chemicals, and the developers in black and white film, lithography, photochemical machining, and microfilm. In particular, hydroquinone and hydroquinone monomethyl ether (4methoxyphenol) are known to inhibit the free radical polymerization during processing and storage in vinyl and acrylic monomer industry, and used as stabilizers in unsaturated polyester resins. ${ }^{3}$ However, hydroquinone and its derivatives are notorious in biological process since they tend to break the aqueous system by oxygen depletion due to high demand of BOD (biological oxygen demand). ${ }^{4,5}$ They also induce tinnitus, nausea, suffocation, shortness of breath, convulsion, delirium, and collapse if more than $1.0 \mathrm{~g}$ per day of hydroquinone or its derivatives are ingested. If more than $5.0 \mathrm{~g}$ per day are ingested, they can induce dermatitis and burn after contact with human skin or cause even death. ${ }^{6}$ Hydroquinone is known to produce the positive response in the micronucleus and an in vitro test for sister chromosome exchange in human lymphocytes. ${ }^{7-9}$ Therefore, investigation of carcinogenic effect for hydroquinone and its derivatives from cosmetic creams, hair products and pharmaceutical preparations is very important in order to avoid health problems. ${ }^{10}$ Several analytical methods such as gas chromatography (GC), high performance liquid chromatography (HPLC), spectrophotometry, and thin layer chromatography (TLC) have been employed for the determination of hydroquinone and its derivatives from biological fluid and health products. ${ }^{11-19}$ Although those analytical techniques have shown good results, problems associated with each method have been issued for many years. For example, HPLC requires an expensive separation or preparation column. In TLC, large amount of sample is necessary due to low sensitivity of the technique. In GC, the application has been narrow since the analytes should be volatile.

Capillary electrophoresis (CE) could be a good method of choice since it provides high separation efficiency, low sample consumption, high separation speed, and high sensitivity. ${ }^{20-23}$ Since study for the investigation of hydroquinone and its derivatives has been rare by using CE, we have applied this technique to the analysis of standard hydro-
\end{abstract}

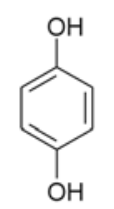

(a)

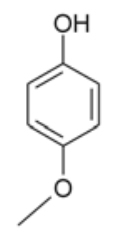

(b)

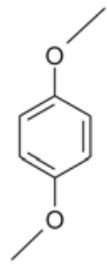

(c)

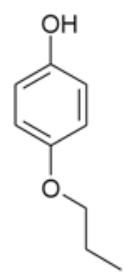

(d)

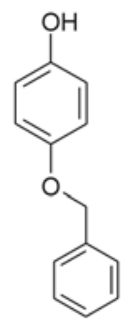

(e)

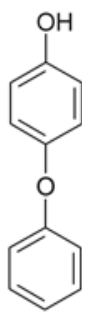

(f)
Figure 1. Structure of HQ and its ether derivatives.

quinone and its derivatives and a cosmetic product (whitening cream) containing hydroquinone using anionic (sodium dodecyl sulfate, SDS) and cationic surfactants (cetyltrimethylammonium bromide, CTAB).

Figure 1 shows the structure of hydroquinone and its derivatives; hydroquinone (HQ, Figure 1-a), hydroquinone monomethyl ether (MHQ, Figure 1-b), hydroquinone dimethyl ether (DMHQ, Figure 1-c), hydroquinone monopropyl ether (PHQ, Figure 1-d), hydroquinone monobenzyl ether (BHQ, Figure 1-e), hydroquinone monophenyl ether (PhHQ, Figure 1-f). When they were separated in $10.0 \mathrm{mM}$ sodium tetraborate buffer, only single peak was observed (data not shown) probably due to the similar polarity of HQ and its derivatives originated from the structural resemblance. In order to improve the selectivity, SDS or CTAB was added in the buffer in our experiment. In micellar electrokinetic chromatography (MEKC), those surfactants are known to improve the resolution by hydrophobic interaction between hydrophobic core inside the micelle and the analyte. ${ }^{24}$

Figure 2 shows the capacity factors of HQ and its derivatives depending on the concentration of SDS and CTAB. As the concentration of each surfactant increased, the capacity factor improved due to the increase of the hydrophobic interaction. Although CTAB was not successful at the concentration above $100.0 \mathrm{mM}$ due to the precipitation of the buffer constituents (no current flow in the capillary observed), relatively high capacity factor was maintained at the concentration above $100.0 \mathrm{mM}$ of SDS. Note that when CTAB was employed in the running buffer, a negative voltage $(-15 \mathrm{kV})$ was applied at the injection side of the capillary since the adsorption of the cationic CTAB molecule to the capillary wall causes the reversal of the 

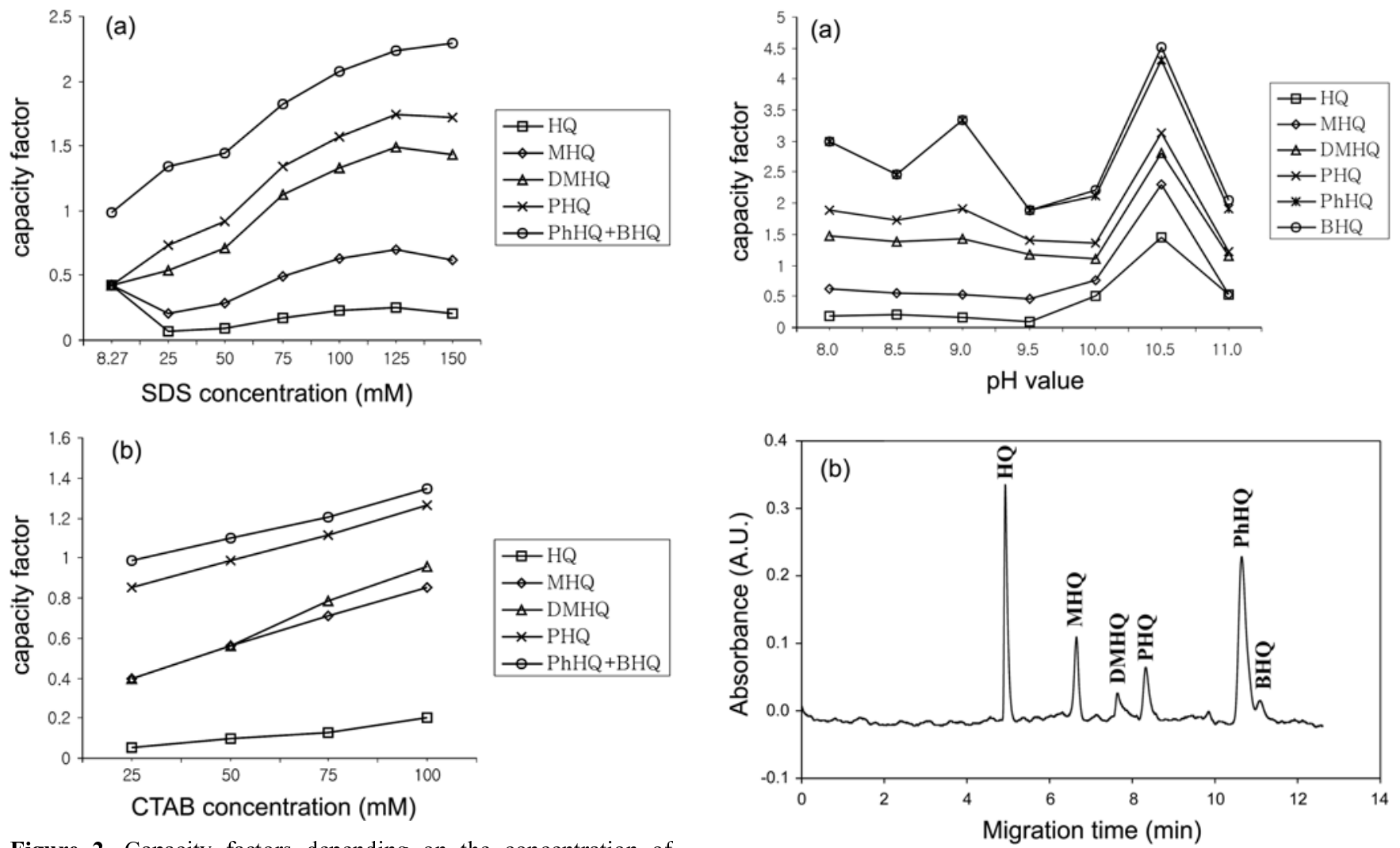

Figure 2. Capacity factors depending on the concentration of surfactants. Experimental conditions: capillary $(75 \mu \mathrm{m}$ I.D., $50 \mathrm{~cm}$ and $40 \mathrm{~cm}$ total and effective lengths, respectively); applied voltage $(15 \mathrm{kV})$; temperature $\left(20^{\circ} \mathrm{C}\right)$; detection (UV absorbance at 254 $\mathrm{nm}$ ); injection (hydrodynamic, $1 \mathrm{sec}$ at $2.0 \mathrm{~cm}$ ); sample concentration $(1.0 \mathrm{mg} / \mathrm{mL})$; the running buffer $(10.0 \mathrm{mM}$ sodium tetraborate buffer). (a) SDS, (b) CTAB (applied voltage, $-15 \mathrm{kV}$ ).

electosmotic flow. Any partial separation of BHQ and PhHQ was not obtained with $\mathrm{CTAB}$ or SDS, and it was attributed to the structural similarity. It seems that difference of one methylene group is not enough to discriminate BHQ and PhHQ in SDS or CTAB micelle.

Figure 3(a) shows the $\mathrm{pH}$ dependence of capacity factor when $100.0 \mathrm{mM}$ of SDS was added in the buffer. The $\mathrm{pH}$ of the buffer was titrated by either hydrochloric acid or sodium hydroxide solution. Capacity factor was generally constant at broad range of $\mathrm{pH}$ except $\mathrm{pH}$ around 10 . Relatively high

Figure 3. (a) Effect of $\mathrm{pH}$ of the running buffer on the values of the capacity factor in $10 \mathrm{mM}$ sodium tetraborate buffer containing 100.0 mM SDS. (b) Electropherogram of standard mixtures of HQ and its ether derivatives at $\mathrm{pH} 10.5$.

separation efficiency was observed for HQ, MHQ, DMHQ, PHQ, BHQ, and PhHQ within $12 \mathrm{~min}$. An interesting fact was that even partial separation of BHQ and PhHQ was obtained (Figure $3 b$ ) at $\mathrm{pH} 10.5$ or higher. The $\mathrm{pKa}$ values of BHQ and PhHQ are 10.9 and 9.9, respectively. ${ }^{25}$ Therefore at $\mathrm{pH}$ higher than 10.5, it seems that PhHQ became more hydrophilic than BHQ, resulting in less interaction with SDS micelle and enhanced migration mobility compared to the mobility of BHQ.

We have applied out technique to the analysis of HQ from commercial whitening cream. HQ has been used as a depigmenter that reduces the formation of epidermal
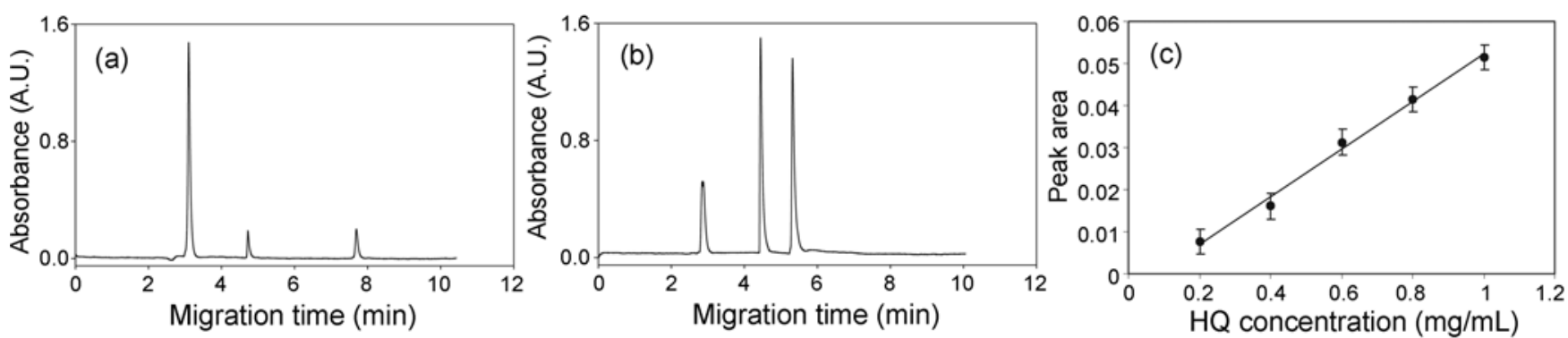

Figure 4. (a) Electropherogram of whitening cosmetic product $B(0.50 \mathrm{mg} / \mathrm{mL})$ in $10.0 \mathrm{mM}$ sodium tetraborate buffer containing $100.0 \mathrm{mM}$ SDS. For other experimental conditions, see Figure 2. (*) HQ, (U) Unknown. (b) Electropherogram of whitening cosmetic product B $(0.50$ $\mathrm{mg} / \mathrm{mL}$ ) in $10.0 \mathrm{mM}$ sodium tetraborate buffer containing $100.0 \mathrm{mM} \mathrm{CTAB}$. (c) Calibration curve with SDS for the standard HQ at the concentrations of $0.20,0.40,0.60,0.80$, and $1.0 \mathrm{mg} / \mathrm{mL}$. 
Table 1. Assay results of the MEKC analysis of HQ from four whitening creams using SDS as the micelle

\begin{tabular}{cc}
\hline Whitening cream & Concentration (w/w \%) \\
\hline A & $5.5 \pm 0.2$ \\
B & $14.7 \pm 0.3$ \\
C & $\mathrm{ND}^{a}$ \\
D & $\mathrm{ND}$ \\
\hline
\end{tabular}

${ }^{a}$ Not detected.

melanin. ${ }^{26,27}$ However, it is now prohibited for any use in cosmetic products by Korean Food and Drug administration (KFDA) since it can cause the dermatitis and burn after the contact with human skin. Four different whitening creams were purchased from local drug stores and analyzed by our MEKC method. Figure 4(a) and (b) show HQ from the whitening cream B by using SDS and CTAB. The presence of HQ was confirmed by spiking with the standard HQ in both Figure 4(a) and (b). The concentration of HQ from this electropherogram was calculated by constructing the calibration curve as shown in Figure 4(c). The regression equation was $\mathrm{y}=0.057( \pm 0.002) \mathrm{x}-0.0043( \pm 0.0002)$ ( $\mathrm{y}$, peak area; $\mathrm{x}$, HQ concentration) with the correlation coefficient of $\mathrm{r}^{2}=0.992$. Table 1 shows the assay results of the MEKC analysis of hydroquinone from four whitening creams. We believe that our MEKC would be a good method of choice for the standard technique of measuring HQ in any commercial products.

\section{Experimental Section}

Capillary electrophoresis. A home-made capillary electrophoresis system was employed in this experiment. An UV detector (Bischoff, Leonberg, Germany) was used for the detection of hydroquinone and its derivatives at $254 \mathrm{~nm}$. For the current monitoring of a capillary filled with the different concentrations of the running buffer, DM-340 digital multimeter (MilTek, CA, USA) was utilized. $\mathrm{pH}$ of the buffer was measured by MP $220 \mathrm{pH}$ meter (Mettler, Toledo, USA). A fused-silica capillary (total length; $50 \mathrm{~cm}$, effective length; $40 \mathrm{~cm}$ ) with i.d. of $75 \mu \mathrm{m}$ and o.d. of $375 \mu \mathrm{m}$ was purchased from Polymicro Technologies (Pheonix, AZ, USA). A high voltage power supply (Spellman, NY, USA) was applied at 15 or $-15 \mathrm{kV}$. For injection, hydrodynamic siphoning at $2.0 \mathrm{~cm}$ for $1 \mathrm{sec}$ was applied. The capillary was pre-cleaned with $\mathrm{H}_{2} \mathrm{O}(5 \mathrm{~min})-0.10 \mathrm{M} \mathrm{NaOH}(10 \mathrm{~min})$ $\mathrm{H}_{2} \mathrm{O}$ (5 min) - the running buffer $(5 \mathrm{~min})$ by using a diaphragm-type pump (GAST Manufacturing, MI, USA). The system was controlled by in-house LabView program and the signal from the UV detector was transferred by LabView interface board to IBM compatible computer.

Buffer and standard solution. The buffer was prepared with sodium tetraborate (Sigma, St. Louis, MO, USA) at the concentration of $10.0 \mathrm{mM}$ in deionized water (Milli-Q reagent water system). Either SDS $(8.3 \mathrm{mM}-150.0 \mathrm{mM}$, Sigma, St. Louis, MO, USA) or CTAB (25.0 mM - 100.0 $\mathrm{mM}$, Sigma, St. Louis, MO, USA) was added in the buffer.
Hydrochloric acid or sodium hydroxide solution was used to titrate $\mathrm{pH}$ of the buffer containing SDS. In order to measure capacity factor $\left(k^{\prime}\right)$, methanol was employed as $t_{0}$ marker. Capacity factor was calculated by the following equation; $k$ ' $=\left(t_{R}-t_{0}\right) / t_{0}$, where $t_{R}$ is the migration time of the analyte. Hydroquinone (Fluka Chemika, Buchs, Switzerland), hydroquinone monomethyl ether (Fluka Chemika, Buchs, Switzerland), hydroquinone dimethyl ether (Fluka Chemika, Buchs, Switzerland), hydroquinone monopropyl ether (Aldrich Chem. Co., WI, USA), hydroquinone monophenyl ether (Fluka Chemika, Buchs, Switzerland), hydroquinone monobenzyl ether (Aldrich Chem. Co., WI, USA) were used at the concentration of $1.0 \mathrm{mg} / \mathrm{mL}$.

Analysis of cosmetic product. Whitening creams were purchased from local drug stores. A $0.005 \mathrm{~g}$ of the sample was dissolved in $10.0 \mathrm{~mL}$ methanol and dispersed for $1 \mathrm{~min}$ with Vortex-Genie 2 (Scientific Industries, NY, USA), then sonicated for $5 \mathrm{~min}$ at $50{ }^{\circ} \mathrm{C}$ by a ultrasonic cleaner (Chosun scientific, Seoul, Korea). After the sample was spinned by a ultracentrifuge (Hanil scientific industrial, Seoul, Korea) for $10 \mathrm{~min}$ at $900 \mathrm{~g}$, the supernatant was filtered by using 0.2 $\mu \mathrm{m}$ membrane filter (Advantec MFS, CA, USA), and injected by siphoning at $2.0 \mathrm{~cm}$ for $1 \mathrm{sec}$. The calibration curve was established at the concentration of $0.20,0.40$, $0.60,0.80$, and $1.0 \mathrm{mg} / \mathrm{mL}$ of pure HQ. In order to ensure any sample loss during pretreatment, pure HQ was treated with the same procedure for the real sample described above.

Acknowledgement. This work was supported by Kyungnam University Research Fund 2004.

\section{References}

1. Rodriguez, I.; Turnes, M. I.; Mejuto, M. I.; Cela, R. J. Chromatogr. A 1996, 721, 297.

2. Rueda, M. E.; Sarabia, L. A.; Herrero, A.; Ortiz, M. C. Analytica Chimica Acta 2003, 479, 173.

3. Parker, S. P. McGraw-Hill Encyclopedia of Chemistry; McGrawHill Press: New York, U. S. A., 1983; pp 500-501.

4. Ullmann, F. Ullmann's Encyclopedia of Industrial Chemistry; Wiley-VCH Press: Weinheim, Germany, 1989; pp 632-655.

5. Katarzyna, B. D.; Magdalena, D.; Adam, V. J. Chromatogr. A 2004, 1052, 233.

6. Martha Windholz The Merck Index; Merck \& Co., Inc. Press: New Jersey, U. S. A., 1976; p 635.

7. Gocke, E.; King, M. T.; Eckhardt, K.; Wild, D. Mutat. Res. 1981, $15,219$.

8. Morimoto, K.; Wolff, S.; Koizumi, A. Mutat. Res. 1983, 119, 355.

9. Anthony, D. Critical Reviews in Toxicology 1999, 29, 283.

10. Takeki, T. Mutation Research 1997, 373, 113.

11. Gagliardi, L.; Amato, A.; Cavazzutti, G.; Chimenti, F.; Bolasco, A.; Tonelli, D. J. Chromatogr. 1987, 404, 267.

12. Buhl, F.; Dul-Zarycta, E.; Chwistek, M. Chem. Anal. (Warsaw) 1988, 33, 819 .

13. Davidkova, P.; Kopecek, J.; Gasparic, J. J. Inf. Rec. Mater. 1989, 17, 117.

14. Burkert, W. G.; Owensby, C. N.; Hinze, W. L. J. Liq. Chromatogr. 1981, 4, 1065.

15. Sakodinskaya, I. K.; Desiderio, C.; Nardi, A.; Fanali, S. J. Chromatogr. 1992, 596, 95. 
16. Penner, N. A.; Nesterenko, P. N. Analyst 2000, 125, 1249.

17. Penner, N. A.; Nesterenko, P. N.; Rybalko, N. A. J. Anal. Chem. 2001, 56, 934.

18. MolnarPerl, I.; Tisza, S.; Koros, E.; KurinCsorgei, K.; Szalai, I. HRC J. High Resolut. Chromatogr. 1995, 18, 749.

19. Pryor, W. A.; Stone, K.; Zang, L. Y.; Bermudez, E. Chem. Res. Toxicol. 1998, 11, 441.

20. Moon, B. G.; Kim, Y. S. Bull. Korean Chem. Soc. 2003, 24, 1203.

21. Choi, H. J.; Kim, Y. S. Bull. Korean Chem. Soc. 2003, 24, 943.

22. Kim, B. J.; Chun, M. S.; Shin, S. M.; Chung, D. S. Bull. Korean Chem. Soc. 1999, 20, 1483.
23. Zhang, Y. P.; Noh, H. J.; Choi, S. H.; Ryoo, J. J.; Lee, K. P.; Ohta, K.; Fujimoto, C.; Jin, J. Y.; Takeuchi, T. Bull. Korean Chem. Soc. 2004, 25, 377.

24. Baker, D. R. Capillary Electrophoresis; John Wiley \& Son Press: New York, U.S.A. 1995; pp 55-60.

25. Weast, R. C.; Selby, S. M.; Hodgman, C. D. Handbook of Chemistry and Physics, $46^{\text {th }}$ ed.; CRC Press: Cleveland, U.S.A., 1965-66; p D-78.

26. Martha Windholz. The Merck Index; Merck \& Co., Inc. Press: New Jersey, U.S.A., 1989; pp 762-763.

27. Swinyard, E. A.; Goodman, L. S. The Pharmacological Basis of Therapeutics; Macmillan Press: New York, U. S. A., 1975; p 955. 